\title{
PCNL in Staghorn Calculi: Our Experience
}

\author{
Mukesh Chandra Arya ${ }^{1}$, Bheru Singh Hariyawat ${ }^{2}$, Vivek Vasudeo ${ }^{2}$, Abhiyutthan Singh Jadaon ${ }^{2}$, Ajay Gandhi², Ankur Singhal ${ }^{2}$ \\ ${ }^{1}$ Senior Professor \& Head, Department of Urology, SP Medical College, Bikaner, Rajasthan, India, ${ }^{2}$ Resident, Department of Urology, SP Medical College, Bikaner, \\ Rajasthan, India.
}

\section{Abstract}

Background: The treatment of STAG HORN calculi has varied from combination of percutaneous nephrolithotomy (PCNL) and shockwave lithotripsy (SWL) or sometimes open surgery. The goals of treatment of a STAG HORN stone are complete stone clearance with minimal morbidity. Although excellent stone-free rates are universally reported in the literature, complication rates vary widely, especially related to the need for blood transfusion. Subjects and Methods: From January 2015 to December 2018, 1400 patients underwent PCNL out of which 392 patients had stag horn stones. Our study included stag horn stones that were present in the renal pelvis and branched into two or more major calyces. All procedures were performed under general or spinal anesthesia by the same surgical team. Results: 392 patients (144 women and $248 \mathrm{men}$ ) with mean age of 44.2 (range $8 \mathrm{yr}-72 \mathrm{yr}$ ) years having partial/complete STAG HORN calculi were treated at our center S.P. Medical college, Bikaner from period of January 2015 to December 2018. 10 patients (10.2\%) had pre existing renal insufficiency with a mean (range) serum creatinine of $3.0(1.5-4.2) \mathrm{mg} / \mathrm{dl}$. Conclusion: PCNL using multiple tracts is safe and effective and should be the first option for renal STAG HORN calculi. It must be done by experienced endourologists in a specialized centre with all the facilities for stone management and treatment of possible complications.

Keywords: Pcnl, Stag Horn, Calculi.

Corresponding Author: Dr. Bheru Singh Hariyawat, M.Ch. Resident, Department of Urology, SP Medical College, Bikaner, Rajasthan, India.

Received: June 2019

Accepted: June 2019

\section{Introduction}

The treatment of STAG HORN calculi has varied from combination of percutaneous nephrolithotomy (PCNL) and shockwave lithotripsy (SWL) or sometimes open surgery. ${ }^{[1]}$ Percutaneous nephrolithotomy (PCNL) for STAG HORN calculi is one of the challenging endourologic procedures. We present here our experience of PCNL in patients with STAG HORN calculi.

\section{Subjects and Methods}

From January 2015 to December 2018, 1400 patients underwent PCNL out of which 392 patients had STAG HORN stones. Our study included STAG HORN stones that were present in the renal pelvis and branched into two or more major calyces (i.e. partial and complete STAG HORN stones).

- Preoperative laboratory investigations included urine analysis and culture, serum creatinine estimation, a complete blood count, liver function tests and prothrombin time.

- Radiological investigations included IVU or noncontrast CT (NCCT). NCCT was used in patients with a high serum creatinine level $(>1.6 \mathrm{mg} / \mathrm{dL})$ or those allergic to the intravenous contrast medium.

- $\quad$ Patients with positive urine cultures were treated with specific antibiotics for 5 days. All patients received intravenous third-generation cephalosporins $1 \mathrm{hr}$ before surgery and continued for $48 \mathrm{hrs}$.

All procedures were performed under general or spinal anesthesia by the same surgical team. After giving anesthesia retrograde ureteral catheterization was done in lithotomy position and then the patient was put in prone position. Fluoroscopy-guided punctures were made and tracks were dilation to 24 French using Alken coaxial metal dilators for the primary tract. A rigid nephroscope of $20 \mathrm{~F}$ was used through an Amplatz sheath. Number of punctures varied from two to four, which was either a supracostal or subcostal. Stones were fragmented and removed using pneumatic lithotripsy and forceps.

Postoperative stone clearance was documented on X-ray KUB. Residual stones were managed by 'second-look' PCNL, while those stones less than $5 \mathrm{~mm}$ were left as such and kept for follow up. The stone-free status was reevaluated after 3 months for patients by X-ray KUB or NCCT.

\section{Results \& Discussion}

392 patients (144 women and 248 men) with mean age of 44.2 (range $8 \mathrm{yr}-72 \mathrm{yr}$ ) years having partial/complete STAG HORN calculi were treated at our center S.P. Medical college, Bikaner from period of January 2015 to December 2018. 10 patients $(10.2 \%)$ had preexisting renal 
insufficiency with a mean (range) serum creatinine of 3.0 $(1.5-4.2) \mathrm{mg} / \mathrm{dl}$. Age wise distribution of the patients has been shown in Table1.

In the primary procedure, number of tracts required per patient were 2 tracts in 192, 3 tracts in 160, 4 tracts in 40 with total of 1024 tracts in 392 renal units.

* Residual stone were noted in 64 patients of whom 40 patients had stone less than $5 \mathrm{~mm}$ and 24 patients had larger residual fragment and underwent second look procedure.

* So a total of 416 procedures were performed in 392 renal units (second-look procedures in 24 renal units).

* In 6 out of 24 (second look procedure) a new tract was needed to remove residual stone, making total number of tracts 1032 .

* The points of entry of these tracts were 390 upper calyx (37.79\%), 562 middle calyx (54.45\%), and 78 lower calyx $(7.55 \%)$.

- 256 puncture were supracostal. Table 2 and table 3 show distribution of total number of tracts and calyx punctured.

* Mean fall (range) in hemoglobin was 1.2 (0.6 -3.8) $\mathrm{mg} / \mathrm{dl}$.

* Mean duration (range) of the procedure was 384 (60125) minutes.

- Complications were

- Blood transfusion $(\mathrm{n}=48)$, accounting for $12.24 \%$ cases

- Fever $(\mathrm{n}=72)$ accounting for $18.36 \%$ cases

- Septic shock $(n=4)$

- Hydrothorax $(\mathrm{n}=1)$

- Cot retention $(\mathrm{n}=1)$

- Death (preexisting renal insufficiency, AKI, septicemia $n=1$ ) as shown in table 4

Table 1: Age wise distribution of patients.

\begin{tabular}{|l|l|l|}
\hline Age (years) & No. of Male & No. of Female \\
\hline $0-10$ & 8 & 0 \\
\hline $11-20$ & 32 & 8 \\
\hline $21-30$ & 20 & 32 \\
\hline $31-40$ & 68 & 44 \\
\hline $41-50$ & 60 & 48 \\
\hline $51-60$ & 28 & 4 \\
\hline$>60$ & 32 & 8 \\
\hline Total & $248(63.26 \%)$ & $144(36.74 \%)$ \\
\hline
\end{tabular}

Table 2: Distribution of total number of tracts
\begin{tabular}{|l|l|l|}
\hline $\begin{array}{l}\text { Number of Tracts } \\
\text { reguired for } \\
\text { surgery }\end{array}$ & Number of cases & $\%$ of patients \\
\hline 1 & 6 & $1.5 \%$ \\
\hline 2 & 192 & $48.24 \%$ \\
\hline 3 & 160 & $40.20 \%$ \\
\hline 4 & 40 & $10.05 \%$ \\
\hline
\end{tabular}

PCNL monotherapy achieved an $93.87 \%$ complete clearance rate at discharge (24 patients had second look procedure). Stone compositions were calcium oxalate $(93 \%)$, uric acid (2\%) and mixed (5\%).
Table 3: Distribution according to the calyx punctured

\begin{tabular}{|l|l|l|l|}
\hline Puncture & Supracostal & Infracostal & $\begin{array}{l}\text { \% of calyx } \\
\text { punctured }\end{array}$ \\
\hline Sup Calyx & 256 & 134 & $37.79 \%$ \\
\hline Mid Calyx & 0 & 562 & $54.45 \%$ \\
\hline Inf calyx & 0 & 78 & $7.55 \%$ \\
\hline
\end{tabular}

Table 4: Table showing total number of complications

\begin{tabular}{|l|l|l|}
\hline Complications & Number of patients & $\begin{array}{l}\text { \% of patients with } \\
\text { complications }\end{array}$ \\
\hline Blood transfusion & 48 & $12.24 \%$ \\
\hline Fever & 72 & $18.36 \%$ \\
\hline Septic shock & 4 & \\
\hline Hydrothorax & 1 & \\
\hline Clot retention & 1 & \\
\hline $\begin{array}{l}\text { Death (pre existing } \\
\text { renal insufficiency + } \\
\text { AKI+ septicemia) }\end{array}$ & 1 & \\
\hline
\end{tabular}

\section{Discussion}

In 1983 Clayman et al. ${ }^{[2]}$ reported the feasibility and safety of PCNL for treating STAG HORN stones. Currently it is the treatment of choice for patients with large, complex and STAG HORN renal stones. ${ }^{[3]}$ The goals of treatment of a STAG HORN stone are complete stone clearance with minimal morbidity. Although excellent stone-free rates are universally reported in the literature, complication rates vary widely, especially related to the need for blood transfusion. ${ }^{[4]}$

Patient counseling is very important before PCNL for STAG HORN stones. The patient must be aware that the chance of needing multiple interventions to become free of stones might be up to $50 \% .^{[5]}$ Though in our study 24 patients required second look procedure $(6.12 \%)$.

Potentially significant morbidity or even death has been reported with PCNL in large-scale series. ${ }^{[6]}$ Furthermore, PCNL is more challenging when used for treating STAG HORN stones. There are many factors that can maximize the benefits of PCNL when treating STAG HORN stones and at the same time minimize the complications. NCCT and contrast-enhanced $\mathrm{CT}$ with three-dimensional reconstruction have helped in better planning of percutaneous access. ${ }^{[7]} \mathrm{A}$ supracostal skin puncture is indicated when there is a large branch of the STAG HORN stone in the upper calyx. It has the benefit of providing an easy access to the renal pelvis and in some cases the lower calyx, through one tract because the surgeon works along the longitudinal axis of the kidney. The main concern of supracostal access is the risk of pleural injury. ${ }^{[8]}$

In STAG HORN stones with multiple large branches, percutaneous access to all the calyces can be difficult through one tract. In these cases the multi-tract technique has been reported as a viable alternative to single-tract PCNL. ${ }^{[9]}$

Most importantly, complete removal of the stone is crucial to eradicate any causative organisms, relieve obstruction and prevent further stone growth. ${ }^{[10]}$ This can be achieved by multiple tracks during the primary or the second-look PCNL or using ESWL to treat residual stones. The surgeon must gain a balance between complete stone clearance and 
acceptable patient morbidity. Therefore, when significant complications develop, e.g. bleeding, the procedure should be terminated and planned for staged PCNL especially if the stone burden is very large.

\section{Conclusion}

PCNL using multiple tracts is safe and effective and should be the first option for renal STAG HORN calculi. It must be done by experienced endourologists in a specialized centre with all the facilities for stone management and treatment of possible complications. Attention to accurate tract selection and placement as well as possession of the full array of endourologic equipment are essential to achieving an excellent outcome. The patients must be informed about the ranges of stone-free and complication rates and the possibility of multiple sessions or secondary procedures.

\section{References}

1. Aron M, Yadav R, Goel R, Kolla SB, Gautam G, Hemal AK, Gupta NP. Multi-tract percutaneous nephrolithotomy for large complete STAG HORN calculi.Urol Int. 2005;75(4):327-32.

2. Clayman R.V., Surya V., Miller R.P., Casteneda Zunega W.R., Amplatz K., Lange P.H. Percutaneous nephrolithotomy; an approach to branched and STAG HORN renal calculi. JAMA. 1983;250:73-75.

3. Morris D.S., Wei J.T., Taub D.A., Dunn R.L., Wolf J.S., Jr, Hollenbeck B.K. Temporal trends in the use of percutaneous nephrolithotomy. J Urol. 2006;175:1731-1736.

4. Soucy F, Ko R, Duvdevani M, Nott L, Denstedt JD, Razvi H.Percutaneous nephrolithotomy for STAG HORN calculi: a single center's experience over 15 years. J Endourol. 2009 Oct;23(10):166973.

5. El-Nahas AR, Eraky I, Shokeir AA, et al. Percutaneous nephrolithotomy for treating STAG HORN stones: 10 years of experience of a tertiary-care centre.Arab Journal of Urology. 2012;10(3):324-329.

6. Michel M.S., Trojan L., Rassweiler J.J. Complications in percutaneous nephrolithotomy. Eur Urol.2007;51:899-906.

7. Desai M., Jain P., Ganpule A., Sabnis R., Patel S., Shervastav P. Developments in technique and technology: the effect on the results of percutaneous nephrolithotomy for STAG HORN calculi. BJU Int.2009; 104:542-548.

8. Munver R., Delvecchio F.C., Newman G.E., Preminger G.M. Critical analysis of supracostal access for percutaneous renal surgery. JUrol. 2001;166:1242-1246.

9. Ganpule A.P., Desai M. Management of the STAG HORN calculus: multiple-tract versus single-tract percutaneous nephrolithotomy. Curr Opin Urol. 2008;18:220-223.

10. El-Nahas A.R., Eraky I., Shokeir A.A., Shoma A.M., El-Assmy A.M., El-Tabey N.A. Long-term results of percutaneous nephrolithotomy for treatment of STAG HORN stones. BJU Int. 2011;108:750-754.

Copyright: (C) the author(s), 2019. It is an open-access article distributed under the terms of the Creative Commons Attribution License (CC BY 4.0), which permits authors to retain ownership of the copyright for their content, and allow anyone to download, reuse, reprint, modify, distribute and/or copy the content as long as the original authors and source are cited.

How to cite this article: Arya MC, Hariyawat BS, Vasudeo V, Jadaon AS, Gandhi A, Singhal A. PCNL in Staghorn Calculi: Our Experience. Asian J. Med. Res. 2019;8(3):SG01-SG03.

DOI: dx.doi.org/10.21276/ajmr.2019.8.3.SG1

Source of Support: Nil, Conflict of Interest: None declared. 